\title{
How prior experience and task presentation modulate innovation in 6-year-old-children
}

\author{
Sonja J. Ebel, Daniel Hanus, and Josep Call
}

\begin{tabular}{|c|c|}
\hline Date of deposit & 30012019 \\
\hline Document version & Author's accepted manuscript \\
\hline Access rights & $\begin{array}{l}\text { Copyright (C) } 2019 \text { Elsevier Inc. All rights reserved. This work is } \\
\text { made available online in accordance with the publisher's policies. } \\
\text { This is the author created, accepted version manuscript following } \\
\text { peer review and may differ slightly from the final published } \\
\text { version. }\end{array}$ \\
\hline $\begin{array}{l}\text { Citation for } \\
\text { published version }\end{array}$ & $\begin{array}{l}\text { Ebel, S. J., Hanus, D., \& Call, J. (2019). How prior experience and } \\
\text { task presentation modulate innovation in 6-year-old-children. } \\
\text { Journal of Experimental Child Psychology, } 180,87-103 .\end{array}$ \\
\hline $\begin{array}{l}\text { Link to published } \\
\text { version }\end{array}$ & https://doi.org/10.1016/j.jecp.2018.12.004 \\
\hline
\end{tabular}

Full metadata for this item is available in St Andrews Research

Repository at: https://research-repository.st-andrews.ac.uk/

\section{St Andrews Research Repository}


1 How prior experience and task presentation modulate innovation in six-year-old children 


\section{Abstract}

Low innovation rates have been found with children until the age of six to eight years in tasks that required them to make a tool. Little is known about how prior experience and task presentation influence innovation rates. In the current study, we investigated these aspects in the floating peanut task (FPT) that required children to pour water into a vertical tube to retrieve a peanut. In three experiments we varied the amount of plants that six-year-olds ( $N$ $=256$ ) watered prior to the task (zero, one or five plants), who watered the plants (child or experimenter) and the distance and salience of the water source. We expected that prior experience with the water would modulate task performance by either boosting innovation rates (facilitation effect) or reducing them since children would possibly learn that the water was for watering plants (functional fixedness effect). Our results indicate robustly low innovation rates in six-year-olds. However, children's performance improved to some extent with increased salience of the water source as well as an experimenter-given hint. Due to the low innovation rates in this age group, we investigated if watering plants prior to the FPT would influence innovation rates in seven-to-eight-year-olds $(N=33)$ for which we did not find evidence. We conclude that six-year-olds struggle with innovation, but that they are more likely to innovate if crucial aspects of the task are made more salient. Thus, although six-year-olds can innovate, they require more physical and social scaffolding than older children and adults.

Keywords: causal understanding, floating peanut task, functional fixedness, innovation, primates, prior experience 


\section{Introduction}

Problem-solving is defined as a process in which individuals evaluate and select appropriate actions to overcome obstacles to fulfil a desired goal (e.g., Deloache, Miller, \& Pierroutsakos, 1998). Prior experience with parts of the problem may have positive or negative effects. For example, experts re-structure problems faster than novices (e.g., in chess, Reingold, Charness, Schultetus, \& Stampe, 2001; Sheridan \& Reingold, 2014).

Nonetheless, people often experience difficulties coming up with novel solutions for familiar problems and they struggle using familiar objects in unfamiliar functional ways (mental set and functional fixedness effect; e.g., Bilalić, McLeod, \& Gobet, 2008b; Duncker, 1945). A subset of problems may be described as innovation tasks that require a creative solution, e.g., to manufacture a tool that you have never made or even used before (e.g., Beck, Apperly, Chappell, Guthrie, \& Cutting, 2011). Such problems cannot be solved by analytical reasoning alone, but require a creative process because the precise path from the starting point to the target state is unspecified (sometimes referred to as "ill-structured problems"; e.g., Cutting, Apperly, Chappell, \& Beck, 2014; Jonassen, 1997).

Recently, Beck and colleagues published a series of studies that required children to make a hook out of a straight pipe cleaner wire to retrieve a bucket with a sticker located at the bottom of a vertical tube (e.g., Beck et al., 2011; Chappell, Cutting, Apperly, \& Beck, 2013; Cutting et al., 2014; see also Weir, Chappell, \& Kacelnik, 2002). Children performed rather poorly in the hook task, but showed a consistent improvement with age, with sixyear-olds showing an innovation rate of about $40 \%$ and eight-year-olds reaching about $60 \%$ (Beck et al., 2011; see also Chappell et al., 2013). Four- to seven-year-old children preferentially selected the bent pipe cleaner when choosing between a straight and a bent 
pipe cleaner, indicating, at least, an understanding of the tool affordances (Beck et al., 2011). Even telling four- to seven-year-old children to produce something out of the given materials or encouraging them to try something did not improve their performance (Chappell et al., 2013; Cutting, Apperly, \& Beck, 2011). This suggests that children's failure was not caused by fear to bend the pipe cleaner or by perseverance with one solution strategy. Interestingly, another study showed that success rates were comparable between three- to five-year-old Bushmen and Western children, indicating that this finding is robust across cultures (Nielsen, Tomaselli, Mushin, \& Whiten, 2014; see also Neldner, Mushin \& Nielsen, 2017)).

Similar age-dependent innovation rates have been found with the floating peanut task (FPT; Hanus, Mendes, Tennie, \& Call, 2011; Mendes, Hanus, \& Call, 2007). This task requires participants to pour water into a vertical tube to obtain a peanut resting on the bottom of the tube and was invented to study non-human great apes' problem-solving (Hanus et al., 2011; Mendes et al., 2007; Tennie, Call, \& Tomasello, 2010). While children used a pitcher, bottle, or a cup in previous studies to transport and pour the water into the tube (Hanus et al., 2011; Nielsen, 2013), great apes transported the water in their mouths and spat it into the tube (Hanus et al., 2011; Mendes et al., 2007; Tennie et al., 2010). Hanus et al. (2011) presented four-, six- and eight-year-old children with the FPT, either with a dry or wet (i.e., quarter-filled) tube. The probability of solving the task steadily increased as a function of age and the tube condition (dry/wet), reaching an innovation rate of about $50 \%$ in six-year-olds and 75\% in eight-year-olds with the wet tube. When Nielsen (2013) tested the FPT with four-year-olds, he found comparable results with nearly none of the children solving the task spontaneously. The hook task and the FPT both require using a familiar object or a liquid in a novel way, and consequently, they represent cases of complex behavioural innovation. The hook task further requires tool manufacture (making a hook), 
something that is not required in the FPT. On the other hand, the solution in the FPT

involved an additional action planning step as it was solely the water source (drinker) not the water itself that was visually available for the subjects while facing the problem.

Prior experience with parts of the problem such as a tool or a specific manipulation can influence task performance in various kinds of problems (e.g. Birch \& Rabinowitz, 1951; Flavell, Cooper, \& Loiselle, 1958; Yonge, 1966) and while some prior experience may lead to a fixation effect, too much experience can cause a reversed pattern. For example, experts in a given field might flexibly choose from different solution strategies because of their great experience (e.g., Bilalić, McLeod, \& Gobet, 2008a; Flavell et al., 1958; Star \& Seifert, 2006). Previous studies suggest that the functional fixedness effect (Duncker, 1945), which entails a fixation on the function of an object, seems to develop around six years of age (e.g., Defeyter \& German, 2003; German \& Defeyter, 2000). German and Defeyter (2000) presented five- to seven-year-old children with a task that required them to use a box that contained several objects in a novel functional way, namely as a support for stacking cuboids. Only six-to-seven-year-olds exhibited a functional fixedness effect while five-yearolds did not (German \& Defeyter, 2000). Cutting et al. (2011) presented four- to seven-yearold children with two tasks, counterbalanced for order across participants. While the hook task required them to bend a pipe cleaner to produce a hook, the unbending task required them to unbend a U-shaped pipe cleaner into a straight wire to poke out a ball from a tube (Cutting et al., 2011). Only few children solved both tasks, and success in the first task did not predict success in the second task. This study suggests that prior experience with bending or unbending of the tool neither facilitated nor hindered children's ability to produce the respective contrasting solution. Chappell et al. (2013) gave four to seven-yearold children the opportunity to explore the materials prior to the hook task to ensure that 
they had experienced the objects' features. Prior exposure did not have an effect on children's performance, indicating no facilitation effect of prior experience with parts of the problem (Chappell et al., 2013). However, a combination of pieces of information seemed to help children in another study. When Cutting et al. (2014) let five-to-six-year-olds explore the materials prior to the test and showed them a template hook, innovation rates increased substantially. Interestingly, this effect was not significant for four-to-five-year-olds and not for the older children when they only explored the materials but did not see the target tool. Hanus et al. (2011) asked four to eight-year-old children to water plants prior to the FPT to familiarize them with the water. This prior experience may have potentially influenced children's performance in the task, although its direction is unclear. On the one hand, drawing children's attention to the water could have facilitated the solution. On the other hand, watering plants prior to the task might have blocked the idea of using the water in a different functional context, i.e., showing a functional fixedness effect.

One aspect that has received little attention regarding functional fixedness is the role of self- vs. other-experience. In other words, is it necessary for an individual to experience the function herself or is it enough to observe the function being used by another person? From the teleological-intentional perspective one would expect that observing the function is enough to establish the idea what the object is for, and indeed some findings suggest that this is the case in children as young as two-and-a-half years of age (e.g. Casler \& Kelemen, 2005; Defeyter, Hearing, \& German, 2009; German \& Johnson, 2002; Hernik \& Csibra, 2009). While previous studies explored whether children assign functions to objects after observing another individual using them, here we focused on whether observing the function would also induce a functional fixedness effect. The FPT seemed a good task to study this effect because it had the right level of difficulty which allowed for a two-sided hypothesis. 
In general, prior experience with a tool can be gained individually or socially and may

be linked to ostensive cues. For example, young children take an actor's intention into account in a task context, which may facilitate problem solving thereafter (Carpenter, Call, \& Tomasello, 2002; Carr, Kendal, \& Flynn, 2015; Huang, 2013). Interestingly, children mainly copy actions that have the desired outcome (Want \& Harris, 2001), even though overimitation (i.e., copying non-efficient actions) is a quite robust phenomenon among younger children (Király, Csibra, \& Gergely, 2013). Moreover, it seems that children's innovative abilities are potentially tempered by a bias towards social learning (Csibra \& Gergely, 2009; Király et al., 2013), which may explain, at least in part, the relatively low innovation rates found in problem-solving tasks (Beck et al., 2011; Cutting et al., 2011; Hanus et al., 2011; Nielsen, 2013). Thus, it is important for children to differentiate between relevant and irrelevant prior experience gained through their own actions or through observation (Williamson, Meltzoff, \& Markman, 2008; Yu \& Kushnir, 2014).

In the current study, we therefore explored the effect of watering plants prior to being confronted with the FPT in six-year-old children and whether it mattered how children experienced this, namely if they watered the plants themselves or they watched an experimenter doing so. We chose six-year-olds because they performed at an intermediate level in the FPT in a previous study, allowing us to entertain a two-sided hypothesis (Hanus et al., 2011). Moreover, the functional fixedness effect seems to develop around the age of six years (Defeyter \& German, 2003; German \& Defeyter, 2000). We implemented the FPT in a game in order to induce positive mood and to decrease social pressure because positive affect seems to facilitate solutions in creative problems (e.g., Lin, Tsai, Lin, \& Chen, 2014). In Experiment $1(N=96)$, we investigated the effect of watering plants prior to the FPT (five, one vs. zero plants) and the impact of whether six-year-old children watered the 
plants themselves or if they observed the experimenter doing so (self- vs. other-experience).

We hypothesized that watering more plants would either have a positive (i.e., facilitating) or a negative (i.e., functionally fixating) effect on innovation rates that would be more profound when the experienced with the water had been gained by children themselves. In Experiment $2(N=64)$, we focused on the influence of the distance to the water (close vs. far) and the condition of the tube (dry vs. wet, i.e., quarter-filled with water). We hypothesized that innovation rates would increase with water being close and this effect would be even more pronounced when the tube already contained water. In Experiment 3 $(N=96)$, we examined the same variables as in Experiment 1 but increased the salience of the water source (bucket close to the tube and transparent). We were again interested if watering plants prior to the FPT and the type of experience would have an impact on innovation rates. In Experiment $4(N=33)$, we focused on seven-to-eight year-old children to assess age changes in performance of some selected conditions of the previous experiments. Half of them got an extensive watering experience (five times) while the other half did not use the water at all prior to the task. We hypothesized again that watering plants could either have a positive or detrimental effect on innovation rates.

\section{Experiment 1}

\section{Methods}

\section{Participants}

Participants were 96 six-year-old children (48 girls; age range: 6.0-6.5 years, mean:

6.2 years). For each of the six conditions, we tested 16 children including the same number 
of girls and boys. Children were recruited from a database of children in kindergartens in a mid-sized German city and some of them had already participated in studies on cognitive development. The socioeconomic background of children was diverse and the parents of the participants had given their informed consent for the study. The study was conducted in a quiet room provided by the kindergartens. Additionally, we tested nine children who were dropped from the study because they either reported to have encountered the task before, e.g., in a teaching context $(N=3)$, because another child had told them the solution $(N=2)$ or because they did not touch the setup $(N=4)$.

\section{Materials}

Two tables ( $\mathrm{L} 59 \mathrm{~cm} \times \mathrm{W} 30 \mathrm{~cm} \times \mathrm{H} \mathrm{50}$ ) were placed next to each other. On one table, there was a Plexiglas tube ( $L 26 \mathrm{~cm} \times W 5 \mathrm{~cm}$ ) attached to a piece of wood, a grey tube (about L $8 \mathrm{~cm} \times W 6 \mathrm{~cm}$, diameter of $4 \mathrm{~cm}$ ), a preserving jar (about $\mathrm{H} 7 \mathrm{~cm}$, diameter $7 \mathrm{~cm}$ ) and a wooden pirate ship ( $L 19.5 \mathrm{~cm} \times \mathrm{W} 17.5 \mathrm{~cm} \times 22.5 \mathrm{~cm}$; see Figure 1). A blue ball made of foam (diameter: $2.5 \mathrm{~cm}$ ) was put inside the vertical tube, a corresponding one in red inside the grey horizontal tube and a yellow one inside the jar (see Figure 1). The table was covered with a white sheet before the children entered. On the other table, five, one or none plants at all were placed in a row (Spathiphyllum, about $22 \mathrm{~cm}$ high; see Figure 1). A round yellow mat was positioned next to the table on the floor (about $89 \mathrm{~cm}$ distance to tube). Depending on the condition, a yellow five-litre bucket $(\mathrm{H} 22.5$, diameter $22 \mathrm{~cm})$ was already standing on the yellow mat (one and five plants condition) or placed at the entrance of the room (zero plants condition). The bucket was filled with water ( $4 \mathrm{~cm}$ ) onto which a blue cup (H $5.5 \mathrm{~cm}$, diameter $6.2 \mathrm{~cm}$ ) was floating. In previous studies, some great apes stopped pouring water into the tube, although they could not yet reach the peanut (Hanus et al., 2011). Thus, we used a bucket and a cup as water source to investigate if children 
would always pour several times to fill the tube as apes sometimes stop after a few spits

207

(Hanus et al., 2011; Tennie et al., 2010). Moreover, we implemented the FPT in a game of colleting three balls to create a positive mood and enhance children's creativity since positive affect seems to help finding solutions in creative problems (e.g., Lin, Tsai, Lin, \& Chen, 2014). When children failed the task, they were presented with an additional task that consisted of a wooden box from which they could easily retrieve another blue ball so that all children succeeded to collect the three balls and gained three stickers as a reward.

\section{Procedure}

We manipulated two factors in a between-subjects design: how many plants were watered (zero, one, five) and who did so (child: self-experience condition, experimenter: other-experience condition). In the two conditions that involved plants, the experimenter asked the children to water the plant(s) with the cup from the water bucket (self-experience) or told the children that she would water the plant(s) with the cup (other-experience). In the condition without any plants present, children were asked to carry the water bucket inside upon entering the room and to place it onto a yellow mat next to the table (self-experience) or the experimenter did so (other-experience). We incorporated the carrying of the bucket action to make children aware of its presence. Thereafter, in all conditions, the experimenter retrieved a pirate ship from underneath the white sheet that covered the experimental setup and told the children that they would get a surprise if they managed to collect three balls and to place them into the ship. While children could retrieve two balls easily form a jar and a horizontal tube, one ball was at the bottom of a long vertical dry tube that required children to pour water into the tube to obtain the ball. After explaining the game, the experimenter revealed the setup by removing the white sheet from the table. She told the children that they could try out whatever came to their minds and sat down at the corner of 
the room because she had "some work to do" (i.e., she worked on a piece of paper without

looking up). The experimenter stated a motivating sentence every minute ("Just try out another thing! Maybe you have another idea?" or "You can try out whatever comes to your mind."). Children had five minutes time to solve the task. In case they did not solve it within this time period, the experimenter would go over and ask them if they had any further ideas what one could try. Children were then allowed to act on the idea if they stated the correct solution (i.e., the experimenter said "You can try out whatever comes to your mind."). When children did not state the correct solution, they received another (easier) task to obtain a blue ball so that in the end, all children completed the game and won a prize, namely three stickers (for a translation from German of the full procedure, see online Supplemental Material).

\section{Coding and analyses}

Children's performance was videotaped. We measured success defined as extracting the blue ball from the vertical tube. We conducted a generalized linear mixed model (GLMM) with a binomial error structure, but it failed to converge due to a floor effect (for details on model formulation, see Experiment 2 and 3).

\footnotetext{
Figure 1. Setup of Experiment 1 (the five plants condition is shown here).
} 


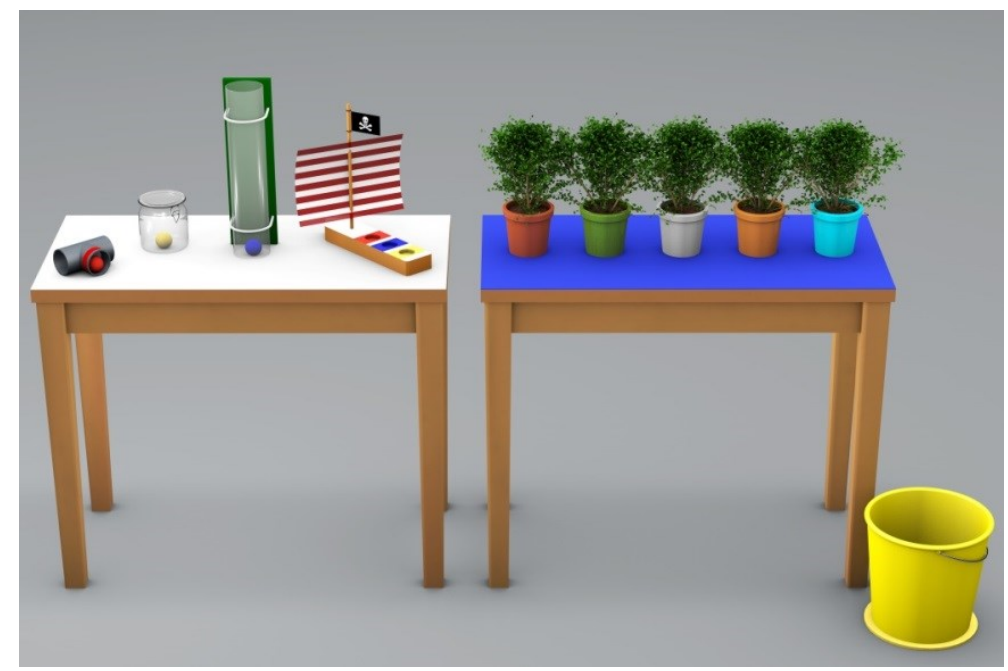

\section{Results and Discussion}

Figure 2 presents the number of children who solved the task as a function of the number of plants watered and the ID of the person who watered them. The extremely low innovation rates prevented us from assessing differences between conditions: Only eight out of 96 children solved the task (8\%). Additionally, one of the unsuccessful children performed a pouring action into the tube with the empty cup, then said "no" and dropped the cup back into the bucket (i.e., no water was poured inside the tube). None of the other unsuccessful children manipulated the cup or stated the solution during the test or when asked for further ideas after five minutes.

This result was quite unexpected as a previous study found that $42 \%$ of the six-yearolds solved the FPT (wet and dry condition pooled together; Hanus et al., 2011). Yet, there are some differences between Hanus et al. (2011) and the current study. Most importantly, the water was presented in a much more salient way in the previous study as the transparent water-filled pitcher was placed onto the table in close proximity of the tube (Hanus et al., 2011). In the current study, the opaque water bucket was placed on the floor 
Figure 2. Results of Experiment 1.

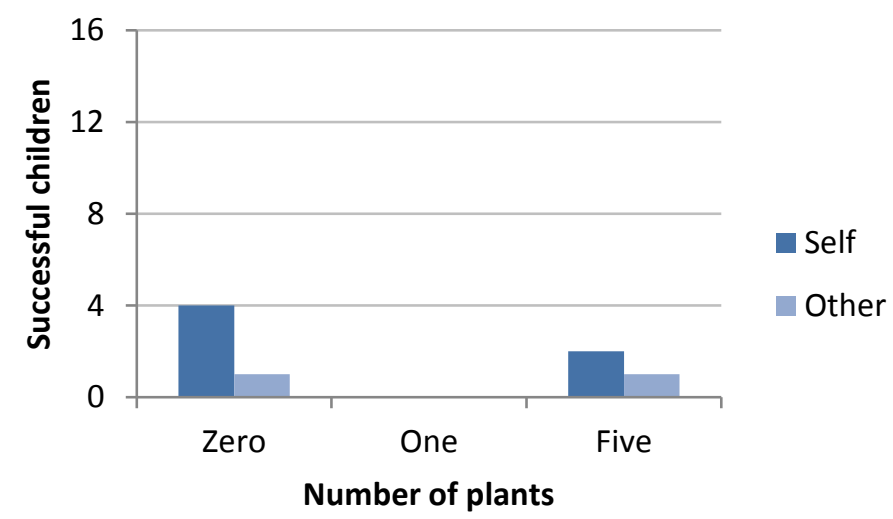
help children to solve the task.

in far distance from the tube. Proximity has been shown to determine which parts of the environment subjects see as the problem space (e.g., Simon \& Newell, 1971).

condition of the tube (dry or wet) to increase water salience of the water as a "tool" and boost innovation rates. Besides, we increased the salience and distance of the water by using a transparent bucket. We hypothesized that the water being closer would especially

\section{Experiment 2}

\section{Methods}

\section{Participants}

Participants were 64 six-year-old children (32 girls; age range: 6.0-6.5 years, mean:

6.2 years). For each of the four conditions, we tested 16 children including the same number of girls and boys. The recruitment of the participants and the testing conditions were the 
same as in Experiment 1. Additionally, we tested twelve children who were dropped from the study because they either reported to have encountered the task before, e.g., in a teaching context $(N=6)$, because another child had told them the solution $(N=5)$ or because they did not touch the setup $(N=1)$.

\section{Materials}

We used the same materials as in Experiment 1 except for the bucket which was replaced by a transparent rectangular one ( $22 \mathrm{~cm} \times \mathrm{W} 17 \mathrm{~cm} \times \mathrm{H} 16 \mathrm{~cm}$; water $\mathrm{H} 5.5 \mathrm{~cm})$. No plants were used in Experiment 2.

\section{Procedure}

We manipulated two factors in a between-subjects design: the distance of the bucket to the tube (close, far) and if there was already water inside the tube (dry, wet). We placed the bucket on the table about $30 \mathrm{~cm}$ to the tube in the close condition while we placed it on the floor next to the table about $89 \mathrm{~cm}$ to the tube in the far condition. The tube was completely dry in the dry condition whereas it was quarter-filled with water in the wet condition. Additionally, all children were asked to carry the bucket with water to its predetermined location to reduce their fear of using it and to let children from the zeroplants condition know about the water bucket. Otherwise, the procedure was the same as in Experiment 1 (see also Figure 3).

\section{Coding and analyses}

We videotaped all trials and scored whether children solved the task as in Experiment 1. We used a GLMM with a binomial error structure with solution (yes / no) as a response (R-package Ime4; Bates, Maechler, Bolker, \& Walker, 2015; R Core Team, 2013). 
The model included distance of water (close / far), tube condition (dry / wet), sex, and age (z-transformed) as predictors, as well as the interaction between distance of water and tube condition. We included kindergarten as random effect into the model. We assessed model stability by comparing the estimates derived by a model based on all data with those obtained from models with levels of the random effect excluded one at a time. Model stability was acceptable. Variance Inflation Factors (VIF; Field, 2005) were derived using the function vif of the R-package car (Fox \& Weisberg, 2011) applied to a standard linear model excluding random effects and interactions, and did not indicate collinearity to be a concern (VIFs < 4). The significance of the full model in comparison to the null model (comprising only the random effects) was assessed using a likelihood ratio test ( $R$ function anova with argument test set to "Chisq"). As a next step, we excluded non-significant interactions from the model and established p-values for the individual effects with likelihood ratio tests comparing the full with respective reduced models (Barr, Levy, Scheepers, \& Tily, 2013; R function drop1).

Figure 3. Setup of Experiment 2 (the dry tube and close water condition is shown here).

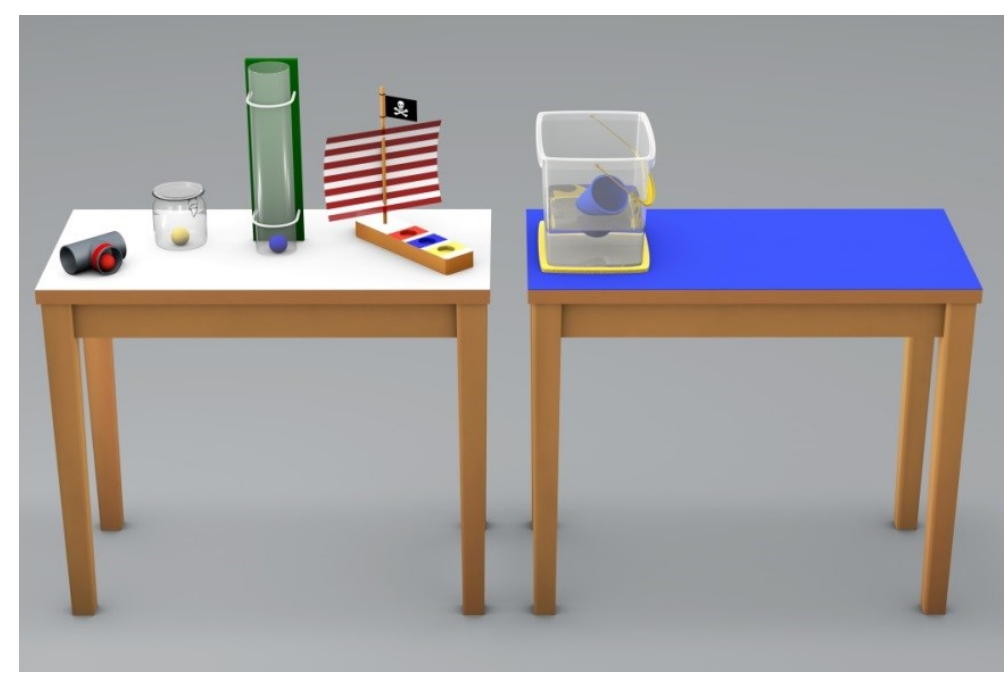


322

\section{Results and Discussion}

Figure 4 presents the number of children who solved the task as a function of the distance of the water to the tube and the tube condition. The full model did not differ significantly from the null model (GLMM; likelihood ratio test: $\chi^{2}=5.35, d f=5, p=0.375$ ) so that we did not investigate the effects of single predictors further. Apparently, there was no significant difference between conditions (close dry: 50\%, close wet: 50\%, far dry: $19 \%$, far wet: $25 \%)$. Only five of the unsuccessful children engaged with the cup during the test: Two children manipulated the cup, two others moved the empty cup (i.e., containing no water) in direction of the tube or touched the tube briefly with it, and one child stated the solution several times, poured water once and then, stopped without retrieving the ball. When asked if she had any further ideas after five minutes, she declined. None of the other children manipulated the cup or stated the solution.

After inspecting the data visually, we decided to run another, exploratory analysis in which we added the interaction of distance of water and sex to the model. The full-nullmodel-comparison revealed a trend (GLMM; likelihood ratio test: $\chi^{2}=11.1, d f=6, p=0.085$ ) and analysing the predictors further indicated that significantly more boys solved the task when the water was close than any other sex and condition combination (Distance of water $x$ Sex, $p=0.017$; boys close: $56 \%$, boys far: $6 \%$, girls close: $38 \%$, girls far: $38 \%)$. Thus, it appears that the salience of the water by using a transparent water bucket and placing the bucket closer to and on the same level as the tube helped some children to come up with the solution. However, our conclusion is only tentative because of the post-hoc exploratory nature of this analysis. 
348 directions, either increasing or decreasing innovation rates.

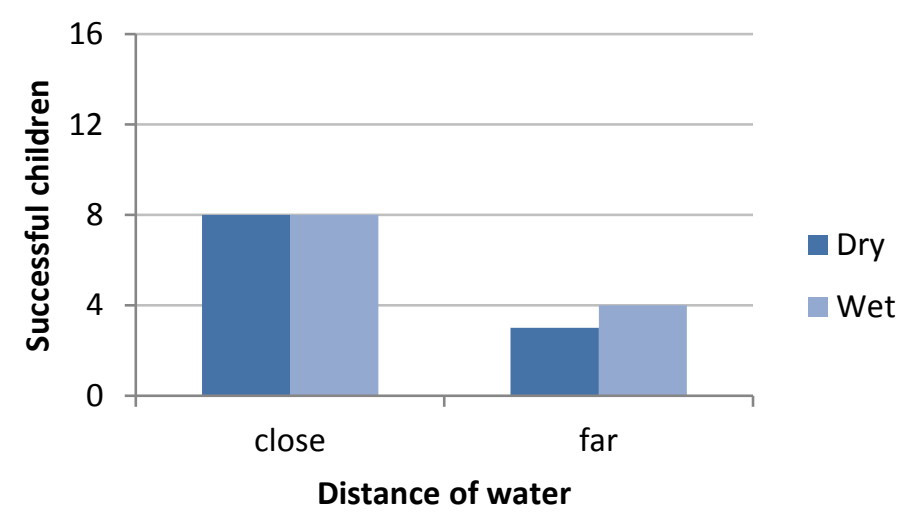

\section{Experiment 3}

\section{Methods}

\section{Participants}

Participants were 96 six-year-old children (48 girls; age range: 6.0-6.5 years, mean:

6.1 years). For each of the six conditions, we tested 16 children including the same number of girls and boys. The recruitment of the participants and the testing conditions were the same as in Experiment 1 and 2. Additionally, we tested 15 children who were excluded from the study because they either reported to have encountered the task before, e.g., in a 
teaching context $(N=4)$, because another child had told them the solution $(N=1)$, because they did not touch the setup at all $(N=3)$, because of experimenter error $(N=3)$ or because of other reasons $(N=4)$.

\section{Materials}

We used the same materials as in Experiment 1, but exchanged the opaque bucket for a transparent one (see Experiment 2).

\section{Procedure}

We investigated two factors in a between-subjects design: how many plants were watered (five, one, zero) and who watered the plants (child: self-experience, experimenter: other-experience). The procedure was the same as in Experiment 1 except for the following changes: The bucket was transparent and it was picked up at the door and placed onto the yellow mat close to the tube in all conditions (distance: $30 \mathrm{~cm}$ ). Moreover, when children had not solved the task after five minutes, the experimenter approached them and asked them if they had any further ideas. If they said "no" to the question, the experimenter took the cup from the bucket and poured water with it once inside the bucket mumbling "hmm" (action demonstration). No eye contact was made during this action to keep it as unintentional as possible. The experimenter then stated that the child may perhaps have another idea and that she will sit down again for a moment. Children had one additional minute to solve the task. Thereafter, they were again asked if they had come up with an idea and eventually received an additional puzzle box to collect a third ball (see procedure of Experiment 1).

\section{Coding and analyses}


and 2 except that the model included number of plants watered, type of experience, sex, and age as predictors, as well as the interaction between number of plants and type of experience and kindergarten as random effect. Model stability and VIFs looked acceptable.

Figure 5. Setup of Experiment 3 (the five plants condition is shown here).

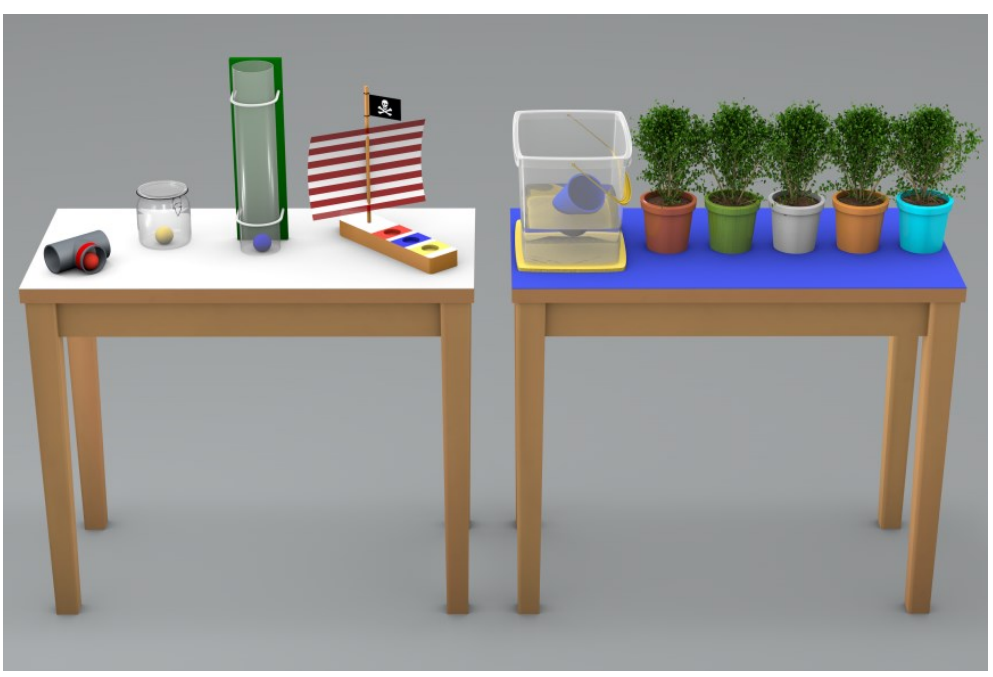

\section{Results and Discussion}

Figure 6 presents the number of children who solved the task as a function of the number of plants watered and the ID of the person who did so. The full-null-modelcomparison did not reach significance (GLMM; likelihood ratio test: $\chi^{2}=4.24, d f=7, p=$ 0.752; Figure 6A). Overall, 21 out of 96 children (22\%) solved the FPT revealing again unexpectedly low innovation rates as in Experiment 1 (Figure 6A). When adding the children who solved the task after receiving an action demonstration, 51 out of 96 children (53\%) solved the task. This resembles $40 \%$ of the children (30 out of 75 ) that had failed to solve the 
task spontaneously (Figure 6B). Thus, relatively few children succeeded after their attention was drawn to the water by the action demonstration. Additionally, $18 \%$ of the unsuccessful children (eight out of 45) engaged with the cup floating in the bucket of water by either manipulating the cup without pouring any water into the tube (1x before action demonstration, $1 x$ after the action demonstration), pouring water into the tube once without retrieving the ball ( $2 x$ after the action demonstration; one of these children also stated the solution) or stating the solution, but without manipulating the cup ( $1 \mathrm{x}$ before the action demonstration, $3 x$ after the action demonstration). Since the model did not reach significance, we could not investigate the effect of sex. In Experiment 2, boys were more likely to solve the FPT when the tool was located close to the tube than when it was far while there was no difference within the girls. Thus, we would have expected them to perform better in Experiment 3 than girls because the tool was always close to the task (success girls: 23/48, boys: $28 / 48$ ). Future studies may follow up on the effect of distance of the tool to the task in relation to sex in innovation problems.

To investigate the impact of the salience of the water, we directly compared overall success rates of Experiment 1 and 3 . At first, we ran a GLMM with a binomial error structure to compare both experiments by adding the variable "experiment" to the previous model ( $N$ = 192). Yet, the model did not converge due to the few solutions in Experiment 1 (and overall) and because of a complete separation with regard to some of the combinations of the conditions (i.e., all participants failed the task). Thus, we collapsed the data across experiments and conducted a Chi-Square test instead. We found that significantly more children innovated in Experiment 3 than in Experiment $1\left(\chi^{2}\right.$-test: $\left.\chi^{2}=5.85, d f=1, p=0.016\right)$. Thus, children were more successful when the water bucket was made more salient (i.e., it was transparent and close to the tube plus it was placed on the table either by the children 
Figure 6. Results for Experiment 3: (A) spontaneous solutions (B) spontaneous solution + action demonstration.

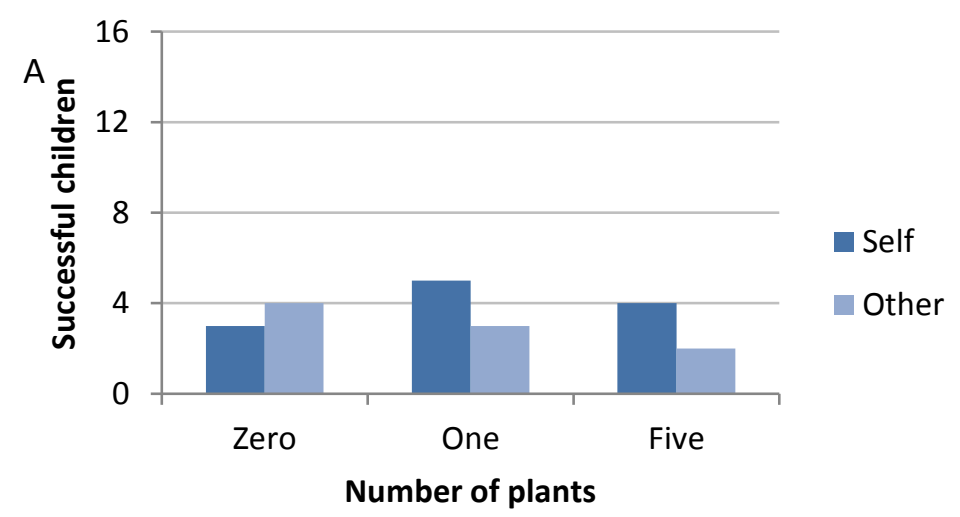

432

B

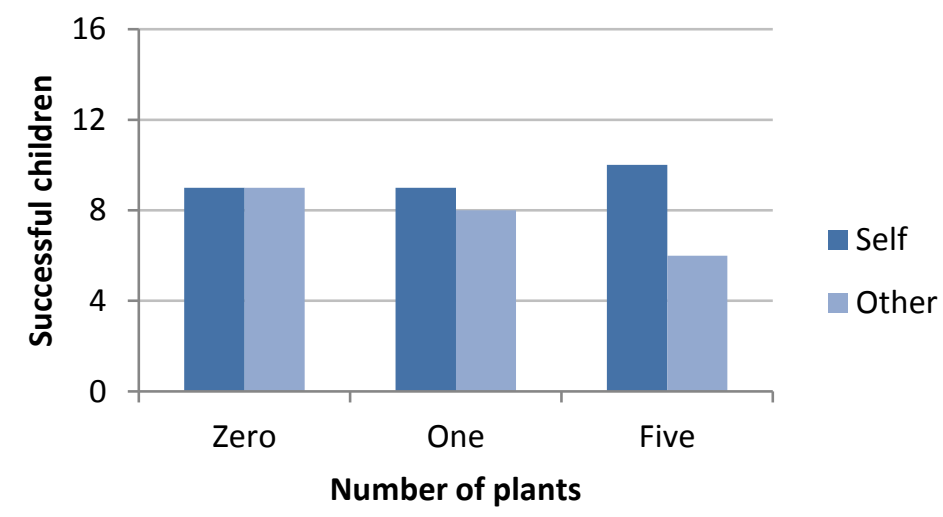




\section{Participants}

Participants were 33 seven-to-eight-year-old children (17 girls; age range: 7.5-8.0

439

440

\section{Materials}

We used the same materials as in the previous experiments, including the transparent bucket from Experiment 2 and 3. The bucket was put on the floor next to the tables as in Experiment 1. We placed the setup on tables provided by the after-school care centres dependent on their sizes since the previously used tables were too small for the older children. As usual, one ball was inside the transparent vertical tube, which was quarter-filled (wet condition). The two additional balls were inside a jar and a piece of tube, which were slightly harder to open compared to the previously used ones to adjust to children's age.

\section{Procedure}


We investigated one factor in a between-subjects design, namely how many plants were watered (five, zero). The bucket was placed on the floor next to the table (as in Experiment 1) before children entered the room and the tube was always wet (i.e., quarter-filled with water as one of the conditions in Experiment 2). The procedure was the same as in the previous experiments, but another trained experimenter conducted the study because the person who had conducted the previous experiments was no longer available.

\section{Coding and analyses}

The same type of binomial model was used to analyse the data as in Experiment 3 but only included the number of plants watered, sex, and age as fixed effects and kindergarten as random effect. Model stability and VIFs looked adequate.

\section{Results and Discussion}

Figure 7 presents the number of children who solved the task as a function of the number of plants watered. The full-null-model-comparison did not reach significance (GLMM; likelihood ratio test: $\chi^{2}=0.88, d f=3, p=0.831$ ). About half of the children solved the task in both conditions (zero plants: $47 \%$, five plants: $50 \%$ ). Since the model did not reach significance, we could not assess the effect of sex on success rates (see Experiment 2). However, since the water was placed far from the tube, we did not expect boys to perform better in this experiment (success girls: 7/17, boys: 9/16). Thus, we neither found a functional fixedness effect, nor a facilitating effect of watering plants prior to the FPT. None of the unsuccessful children manipulated the cup during the test or poured water into the tube. 
Figure 7. Results of Experiment 4.

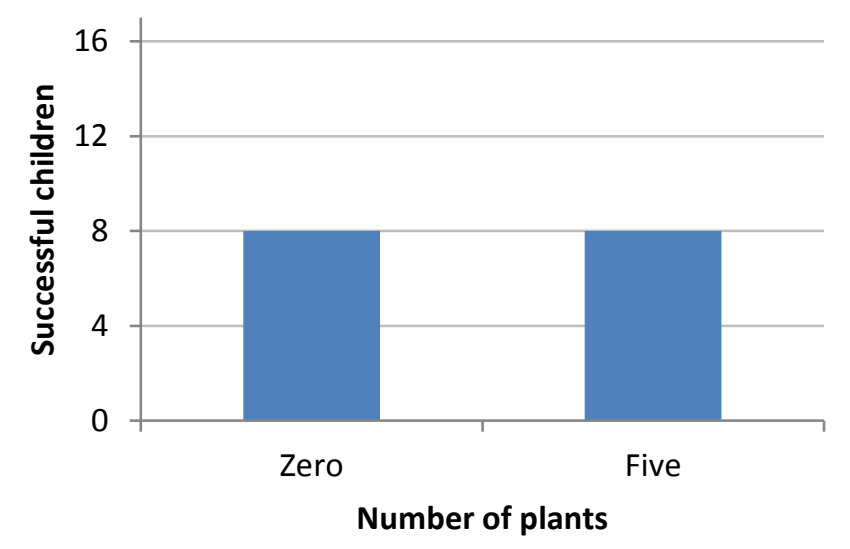

\section{General Discussion}

We did not find evidence for a functional fixedness effect with regard to prior experience (i.e., watering plants) in the floating peanut task in six-year-old children despite repeated attempts. Overall, innovation rates in six-year-olds remained very low with $20 \%$ solving the task (pooled data from Experiment 1-3, 52/256 children, excluding children who succeeded after an action demonstration). Performance in this age group improved when the salience of the water bucket was increased by placing a transparent bucket close to the tube (Experiment 3) compared to an opaque one far away from the tube (Experiment 1). An additional non-social cue (tube quarter-filled with water) did not have an effect. However, an action demonstration, which consisted of the experimenter pouring water inside the bucket once, also improved success rates (Experiment 3). We could not assess the impact of the ID of the person watering the plants (child or experimenter) due to overall low innovation rates 
has been obtained in recent studies that made use of the hook task that required children to bend a hook out of a pipe cleaner to retrieve a bucket from a vertical tube (e.g., Beck et al., 2011; Cutting et al., 2011). While recent studies suggest the same level of difficulty for the

FPT and the hook task in six-year-olds (about 40-50\% of children succeed; Beck et al., 2011;

Chappell et al., 2013; Hanus et al., 2011), the current study indicates that the FPT is harder

to solve than the hook task as a smaller proportion of children found the solution (about

$20 \%$ overall). Yet, the FPT might have been harder to solve in the current study because its implementation differed in the following ways from the previous study (Hanus et al., 2011).

First, the current setup included several objects placed next to the tube (a pirate ship, plants, two containers and two additional target objects) which may have misdirected children as evidenced by their attempts to insert them into the tube, even though they were obviously too large to fit into the tube. In contrast, Hanus et al. (2011) presented children with a tube and a water pitcher only, something that narrowed down the number of possible manipulations or distractions. Moreover, we cannot rule out that children's success at extracting the two other balls easily with their hands only hindered their ability to extract the ball from the tube. However, this explanation is weakened by the fact that many children in Hanus et al. (2011) also tried to extract the reward with their fingers repeatedly, even though they had not experienced extracting a similar rewards easily prior to the test (unpublished data). Moreover, children in the current study mainly focused their attention (expressed verbally or by visual inspection) on the long vertical tube, often immediately after uncovering the setup. And when they turned their attention to the easily obtainable balls, they did not seem too engaged with them before or after collecting them. 
520

(2011), which potentially led to fewer children solving the task because they had less time to do so. However, we decided to shorten our test period because most solutions occurred early during the test in the previous study (unpublished data). Thus, we consider it unlikely that the short test period has caused the low innovation rates. Third, unlike Hanus et al. (2011), we used a bucket filled with water on which a cup was floating. Perhaps, children were more likely to associate the water pitcher employed by Hanus et al. (2011) with a pouring action than the bucket and the cup. Note that the cup that we used had neither a handle nor a spout, thus reinforcing the notion that it may have had different affordances than the pitcher (Gibson, 1982).

Similar to our results, Beck and colleagues did not find evidence that various changes in the procedure would increase innovation rates in the hook task (e.g., children getting bending experience or being explicitly told to produce something out of the materials), indicating that low innovation rates at this age is a robust phenomenon (Chappell et al., 2013; Cutting et al., 2011), also across cultures (Nielsen et al. 2014; Neldner et al., 2017).

Only bending experience combined with seeing the end-state of the tool increased innovation rates notably in five- to six-year-olds but not in younger children (Cutting et al., 2014). The authors concluded that younger children struggle to recombine pieces of information (e.g., Cutting et al., 2014), especially in so called "ill-structured problems" in which only the start and the goal state are known but not the steps in between (Cutting et al., 2014; Jonassen, 1997). The current study suggests that the FPT may share these features with the hook task and that six-year-olds face difficulties solving this type of tasks. However, future research is needed to compare more directly the cognitive mechanisms underlying the hook and the FP tasks. 
the FPT when compared to others or the number of watered plants. One possibility why we did not find the effect could be that we used a water bucket instead of a pitcher or a bottle that was used in previous studies (Hanus et al., 2011; Nielsen, 2013). Buckets are commonly used for multiple purposes but they are associated with pouring water less often than pitchers and bottles. It would be interesting to use a watering can instead, which is made for watering plants (see also Defeyter \& German, 2003; Defeyter et al., 2009; Hernik \& Csibra, 2009; Ruiz \& Santos, 2013). Another possibility why we did not find an effect could be that five pouring actions were not enough to establish a 'fixed function'. Future studies could explore how much exposure is needed to induce a functional fixedness effect in humans children as well as adults (see also Flavell et al., 1958; Yonge, 1966). et al., 2013), innovation may be boosted when children are given hints towards the solution. Hints may be given in a non-social way (i.e., by the relations of the objects involved in a practical task) or in a social way (i.e., by an agent). Innovation rates in the current study increased when children received a non-social cue about the tool by increasing the salience of the water bucket: When the bucket was transparent and placed close to the tube, children were more likely to succeed (comparing Experiment 1 and 3). Interestingly, boys seemed to benefit from the tool being close to the task more than girls in Experiment 2, but this difference was not replicated in the subsequent experiment. Nevertheless, future studies are needed to further investigate the potential interaction effect between sex and tool-distance in the FPT. the bucket as part of the problem space and therefore as a potential "tool" (see also Neldner 
et al., 2017). Interestingly, water that was already located inside the tube did not have the same effect in six-year-olds (Experiment 2). However, when Hanus et al. (2011) presented four-, six- and eight-year-olds with a dry or a wet tube, they found increased innovation rates with age and tube condition (i.e., children were more likely to solve the task with a wet tube). However, when focusing exclusively on six-year-olds, only two additional children solved the FPT when there was already water located inside the tube (33\% dry, 50\% wet), indicating no major difference within this age group. Taken together, these two studies suggest that six-year-olds did not understand that the water inside the tube was a hint to the solution, perhaps because it did not draw their attention to towards the "tool source" itself (i.e., the water bucket).

Some children in the current study only innovated after they had received a hint in the form of an action demonstration: They benefitted from observing the experimenter pouring water with the cup inside the water bucket once, thus, drawing the attention to the tool and the action required. After receiving this hint, $40 \%$ of the children who initially failed $(N=30)$ came up with the correct solution. In a recent study, Nielsen (2013) presented fouryear-olds with the FPT and $86 \%$ failed to solve the task. Unsuccessful children then received one of three social demonstrations: They either watched how the experimenter poured a little bit of water from a bottle into the tube, poured the water into a small cup and then into a tube, or observed the experimenter executing the same procedure, but using a large cup. About $60 \%$ of children solved the task after receiving a demonstration, mostly by employing the same technique as the experimenter. While in both studies the required action was demonstrated, only in Nielsen et al. (2013) the experimenter poured water into the tube. Thus, children could imitate the precise actions (including the required end state) to solve the task, whereas in the current study they additionally had to see the water in the 
bucket as a means to solve the FPT. Although other explanations are possible, it is likely that making the water more salient by directly pouring it into the tube explains children's differential success in these studies.

It is a fascinating question how social learning (especially imitation) relates to innovation in children in general and learning about objects in particular. Human children benefit massively from social learning (e.g., Behne et al., 2005; Csibra \& Gergely, 2009; Wood, Kendal, \& Flynn, 2013) which sometimes leads to imitation of irrelevant actions ("overimitation", e.g. Lyons, Young, \& Keil, 2007), which is potentially stronger in male participants (Frick, Clément, \& Gruber, 2017). Thus, there may be no need for innovative abilities in younger children because they can rely on older group members and their main learning focus lies on copying others rather than learning individually (e.g., Csibra \& Gergely, 2009; Király et al., 2013). For example, Carr et al. (2015) found few instances of innovations in a multi-methods puzzle box in human children, whereas many children copied demonstrated actions, again suggesting a bias towards imitation over individual innovation. So while children are known to be creative in their playful behaviour (Bateson \& Martin, 2013), this creativity does not seem to help them with innovation that require the goaldirected recombination of objects. At the same time, however, they seem able to incorporate social information to find solutions to such tasks.

The teleological-intentional stance proposes that humans represent objects as being made for a specific purpose by an agent (e.g., Defeyter \& German, 2003; Defeyter et al., 2009; German, Truxaw, \& Defeyter, 2007; Hernik \& Csibra, 2009; Ruiz \& Santos, 2013). Thus, functions of objects are mainly learned socially and even when no other agent is present children may infer objects' intended functions. It is an open question how the social embeddedness of objects relates to functional fixedness. Functional fixedness was originally 
conceived in a purely mechanical (asocial) framework, yet, learning about the function of an object also involves an intentional and normative dimension. Even the classical box and candle problem, in which a box first serves as container and then as support for a candle (Duncker, 1945), can be conceived from the teleological-intentional stance as "boxes are designed and created to contain things" and normatively as "things go inside boxes". It is an open question if one can cleanly separate the social from the purely mechanical dimension and our study was not designed with this goal in mind. However, we varied how the child learned about the function of the tool, that is, either the child herself or the experimenter watered the plants. Yet, the condition, in which the child waters the plants, is not purely about individual learning because the experimenter asks her to do so and is present throughout the test period. Since we did not find a functional fixedness effect, we could not draw any conclusions about the impact of self- vs. other-experience. We had hypothesized that children may exhibit a stronger effect when they directly implement a function than when they observe someone implementing it because one's own action might be more memorable (- although one may also hypothesize the contrary outcome when considering the intentional and normative dimension). Yet, this is another aspect that remains under studied and which deserves further research attention. Moreover, it would be important to investigate factors modulating the functional fixedness effect in slightly older children since this phenomenon only emerges around the age of six years (e.g., Defeyter \& German, 2003; German \& Defeyter, 2000) and the children in the current study had just turned six.

Another reason for the low innovation rates is that children hesitated to use water indoors for fear of spilling it on the floor. Many children indeed asked if they could use the water before doing so, even in the wet condition in which there was already some water located inside the tube. To reduce fear of using the water, we told children spilling water 
was no problem when they watered the plants. We also encouraged them to try out any idea they had. After the test, we asked them for further ideas to give them a chance to state the solution to rule out that they did not dare to act on their correct idea. It would still be interesting to present children with the FPT on an outdoor playground to lower the hesitation to employ water as well as to remove the constraints of a test situation (see Bonawitz et al., 2009). Besides, there is no evidence that low innovation rates in the hook task can be explained by children's hesitation to manipulate the target object, namely bending the pipe cleaner (Cutting et al., 2011). In sum, children may hesitate to employ the water in the FPT but it is unlikely that this is the main reason why they struggled with this problem.

Finally, children showed a clear pattern when it comes to pouring water into the tube. Once they had the idea, they continued pouring the water until they could reach the ball. Only three of the 101 children (3\%) who poured water into the tube in the course of the four experiments stopped pouring water into the tube after their initial cup (i.e., not solving the task; $1 \%$ of all 289 children tested). In two of those three cases they added so little water that the ball did not even float. It is an open question if children disregarded this solution or if they were uncertain about them being allowed to use the water. Recent studies showed a slightly different pattern in non-human great apes, with some of them acting like the children while others stopped adding water without obtaining the peanut (e.g. Hanus et al., 2011). Children often stated the solution before employing it, probably to make sure that they were allowed to use the water. Thus, they clearly anticipated the outcome of their actions. Encountering a quarter-filled tube helped neither six-year-old children nor apes (Experiment 2; Hanus et al., 2011). This is surprising as a quarter filled tube constitutes a partial solution and we know that very young children and non-human great apes benefit 
663 from encountering the full solution (the "end-state", e.g. Bellagamba \& Tomasello, 1999;

664 Huang, Heyes, \& Charman, 2002; Tennie et al., 2010). Only by the age of eight years, children 665 seem to benefit fundamentally from encountering a partial solution in the FPT (Hanus et al., 666 2011). experience in the floating peanut task in six-year-olds. Yet, we found robust low innovation rates. A non-social hint (proximity and visibility of the water) and a social hint (an action demonstration) increased performance though overall innovation rates still stayed modest.

Nonetheless, a minority of children found the innovative solution suggesting that some sixyear-olds have the capacity to innovate, but that they may be more dependent on greater physical and social scaffolding than older children and adults.

\section{References}

Barr, D. J., Levy, R., Scheepers, C., \& Tily, H. J. (2013). Random effects structure for confirmatory hypothesis testing: Keep it maximal. Journal of Memory and Language, 68(3), 255-278. doi:10.1016/j.jml.2012.11.001

Bates, D., Maechler, M., Bolker, B., \& Walker, S. (2015). Fitting linear mixed-effects models using Ime4. Journal of Statistical Software, 67(1), 1-48.

Bateson, P., \& Martin, P. (2013). Play, playfulness, creativity and innovation. Cambridge: Cambridge University Press.

Beck, S. R., Apperly, I. A., Chappell, J., Guthrie, C., \& Cutting, N. (2011). Making tools isn't child's play. Cognition, 119(2), 301-306. doi:10.1016/j.cognition.2011.01.003 
Behne, T., Carpenter, M., \& Tomasello, M. (2005). One-year-olds comprehend the communicative intentions behind gestures in a hiding game. Developmental Science, 8(6), 492-499. doi:10.1111/j.1467-7687.2005.00440.x

Bellagamba, F., \& Tomasello, M. (1999). Re-enacting intended acts: comparing 12- and 18-montholds. Infant Behavior \& Development, 22(2), 277-282.

Bilalić, M., McLeod, P., \& Gobet, F. (2008a). Inflexibility of experts-Reality or myth? Quantifying the Einstellung effect in chess masters. Cognitive Psychology, 56(2), 73-102. doi:http://dx.doi.org/10.1016/j.cogpsych.2007.02.001

Bilalić, M., McLeod, P., \& Gobet, F. (2008b). Why good thoughts block better ones: The mechanism of the pernicious Einstellung (set) effect. Cognition, 108(3), 652-661. doi:10.1016/j.cognition.2008.05.005

Birch, H. G., \& Rabinowitz, H. S. (1951). The negative effect of previous experience on productive thinking. Journal of Experimental Psychology, 41(2), 121-125. doi:10.1037/h0062635

Bonawitz, E., Shafto, P., Gweon, H., Chang, I., Katz, S., \& Schulz, L. (2009, July29th-Aug.1st). The double-edged sword of pedagogy: modeling the effect of pedagogical contexts on preschoolers' exploratory play. Paper presented at the 31st Annual Meeting of the Cognitive Science Society, CogSci, VU University Amsterdam, Netherlands.

Carpenter, M., Call, J., \& Tomasello, M. (2002). Understanding "prior intentions" enables two-yearolds to imitatively learn a complex task. Child development, 73(5), 1431-1441.

Carr, K., Kendal, R. L., \& Flynn, E. G. (2015). Imitate or innovate? Children's innovation is influenced by the efficacy of observed behaviour. Cognition, 142, 322-332.

Casler, K., \& Kelemen, D. (2005). Young children's rapid learning about artifacts. Developmental Science, 8(6), 472-480. doi:10.1111/j.1467-7687.2005.00438.x

Chappell, J., Cutting, N., Apperly, I. A., \& Beck, S. R. (2013). The development of tool manufacture in humans: what helps young children make innovative tools? Philosophical Transactions of the Royal Society B-Biological Sciences, 368(1630). doi:10.1098/rstb.2012.0409 
Csibra, G., \& Gergely, G. (2009). Natural pedagogy. Trends in Cognitive Sciences, 13(4), 148-153. doi:10.1016/j.tics.2009.01.005

Cutting, N., Apperly, I. A., \& Beck, S. R. (2011). Why do children lack the flexibility to innovate tools? Journal of Experimental Child Psychology, 109(4), 497-511. doi:10.1016/j.jecp.2011.02.012

Cutting, N., Apperly, I. A., Chappell, J., \& Beck, S. R. (2014). The puzzling difficulty of tool innovation: Why can't children piece their knowledge together? Journal of Experimental Child Psychology, 125, 110-117. doi:10.1016/j.jecp.2013.11.010

Defeyter, M. A., \& German, T. P. (2003). Acquiring an understanding of design: evidence from children's insight problem solving. Cognition, 89(2), 133-155.

Defeyter, M. A., Hearing, J., \& German, T. C. (2009). A developmental dissociation between category and function judgments about novel artifacts. Cognition, 110(2), 260-264. doi:10.1016/j.cognition.2008.10.014

Deloache, J. S., Miller, K. F., \& Pierroutsakos, S. L. (1998). Reasoning and problem solving. In W. Damon, D. Kuhn, \& R. S. Siegler (Eds.), Handbook of child psychology. Cognition, perception, and language (5th ed., Vol. 2). New York: John Wily \& Sons, Inc.

Duncker, K. (1945). On problem-solving. Psychological Monographs, 58(5), 1-112.

Field, A. P. (2005). Is the meta-analysis of correlation coefficients accurate when population correlations vary? Psychological Methods, 10(4), 444-467. doi:10.1037/1082-989x.10.4.444

Flavell, J. H., Cooper, A., \& Loiselle, R. H. (1958). Effect of the number of pre-utilization functions on functional fixedness in problem-solving. Psychological Reports, 4(2), 343-350.

Fox, J., \& Weisberg, S. (2011). An \{R\} Companion to Applied Regression. Thousand Oaks CA: Sage. Retrieved from http://socserv.socsci.mcmaster.ca/jfox/Books/Companion

Frick, A., Clément, F., \& Gruber, T. (2017). Evidence for a sex effect during overimitation: boys copy irrelevant modelled actions more than girls across cultures. Royal Society open science, 4(12). 
German, T. P., \& Defeyter, M. A. (2000). Immunity to functional fixedness in young children. Psychonomic Bulletin \& Review, 7(4), 707-712. doi:10.3758/bf03213010

German, T. P., \& Johnson, S. C. (2002). Function and the Origins of the Design Stance. Journal of Cognition and Development, 3(3), 279-300. doi:10.1207/s15327647jcd0303_2

German, T. P., Truxaw, D., \& Defeyter, M. A. (2007). The role of information about "convention," "design," and "goal" in representing artificial kinds. New Directions for Child Adolescent Development (115), 69-81.

Gibson, E. L. (1982). The concept of affordances in development: the renascence of functionalism. In W. A. Collins (Ed.), The concept of development: the Minnesota symposia on child psychology (15), 55-81.

Hanus, D., Mendes, N., Tennie, C., \& Call, J. (2011). Comparing the performances of apes (Gorilla gorilla, Pan troglodytes, Pongo pygmaeus) and human children (Homo sapiens) in the floating peanut task. PLoS One, 6(6), e19555. doi:10.1371/journal.pone.0019555

Hawkes, K., O'Connell, F., \& Blurton Jones, N. G. (1995). Hadza children's foraging: juvenile dependency, social arrangements, and mobility among hunter-gatherers. Current Anthropology, 36(4), 688-700.

Hernik, M., \& Csibra, G. (2009). Functional understanding facilitates learning about tools in human children. Current Opinion in Neurobiology, 19(1), 34-38. doi:10.1016/j.conb.2009.05.003

Huang, C.-T., Heyes, C., \& Charman, T. (2002). Infants' behavioral reenactment of "failed attempts": Exploring the roles of emulation learning, stimulus enhancement, and understanding of intentions. Developmental Psychology, 38(5), 840-855. doi:10.1037/0012-1649.38.5.840

Huang, C. T. (2013). Contexts of a person's prior intentions facilitate observational learning in 2.5year-old children. Cognitive Development, 28(4), 374-385. doi:10.1016/j.cogdev.2013.05.003 Jonassen, D. H. (1997). Instructional design models for well-structured and ill-structured problemsolving learning outcomes. Educational Technology Research and Development, 45(1), 65-94. doi:10.1007/bf02299613 
Király, I., Csibra, G., \& Gergely, G. (2013). Beyond rational imitation: Learning arbitrary means actions from communicative demonstrations. Journal of Experimental Child Psychology, 116(2), 471486. doi:https://doi.org/10.1016/j.jecp.2012.12.003

Lin, W. L., Tsai, P. H., Lin, H. Y., \& Chen, H. C. (2014). How does emotion influence different creative performances? The mediating role of cognitive flexibility. Cognition \& Emotion, 28(5), 834844. doi:10.1080/02699931.2013.854195

Lyons, D. E., Young, A. G., \& Keil, F. C. (2007). The hidden structure of overimitation. Proceedings of the National Academy of Sciences of the United States of America, 104(50), 19751-19756. doi:10.1073/pnas.0704452104

Mendes, N., Hanus, D., \& Call, J. (2007). Raising the level: orangutans use water as a tool. Biology letters, 3(5), 453-455. doi:10.1098/rsbl.2007.0198

Neldner, K., Mushin, I., \& Nielsen, M. (2017). Young children's tool innovation across culture: Affordance visibility matters. Cognition, 168, 335-343. doi:https://doi.org/10.1016/j.cognition.2017.07.015

Nielsen, M. (2013). Young children's imitative and innovative behaviour on the floating object task. Infant and Child Development(22), 44-52. doi:10.1002/icd

Nielsen, M., Tomaselli, K., Mushin, I., \& Whiten, A. (2014). Exploring tool innovation: a comparison of Western and Bushman children. Journal of experimental child psychology, 126, 384-394. doi:10.1016/j.jecp.2014.05.008

R Core Team. (2013). R: A language and environment for statistical computing. Vienna, Austria: R Foundation for Statistical Computing. Retrieved from http://www.R-project.org/

Reingold, E. M., Charness, N., Schultetus, R. S., \& Stampe, D. M. (2001). Perceptual automaticity in expert chess players: Parallel encoding of chess relations. Psychonomic Bulletin \& Review, 8(3), 504-510. doi:10.3758/bf03196185

Ruiz, A. M., \& Santos, L. R. (2013). Understanding differences in the way human and non-human primates represent tools: The role of teleological-intentional information. In C. M. Sanz, J. 

Call, \& C. Boesch (Eds.), Tool use in animals. Cognition and ecology. Cambridge: Cambridge University Press.

Sheridan, H., \& Reingold, E. M. (2014). Expert vs. novice differences in the detection of relevant information during a chess game: evidence from eye movements. Frontiers in Psychology, 5. doi:10.3389/fpsyg.2014.00941

Simon, H. A., \& Newell, A. (1971). Human problem solving: the state of the theory in 1970. American Psychologist, 26(2), 145-159. doi:10.1037/h0030806

Star, J. R., \& Seifert, C. (2006). The development of flexibility in equation solving. Contemporary Educational Psychology, 31(3), 280-300. doi:http://dx.doi.org/10.1016/j.cedpsych.2005.08.001

Tennie, C., Call, J., \& Tomasello, M. (2010). Evidence for emulation in chimpanzees in social settings using the floating peanut task. PLoS One, 5(5), e10544. doi:10.1371/journal.pone.0010544

Want, S. C., \& Harris, P. L. (2001). Learning from other people's mistakes: Causal understanding in learning to use a tool. Child Development, 72(2), 431-443.

Weir, A. A. S., Chappell, J., \& Kacelnik, A. (2002). Shaping of hooks in new Caledonian crows. Science, 297(5583), 981-981. doi:10.1126/science.1073433

Williamson, R. A., Meltzoff, A. N., \& Markman, E. M. (2008). Prior experiences and perceived efficacy influence 3-year-olds' imitation. Developmental Psychology, 44(1), 275-285. doi:10.1037/0012-1649.44.1.275

Wood, L. A., Kendal, R. L., \& Flynn, E. G. (2013). Whom do children copy? Model-based biases in social learning. Developmental Review, 33(4), 341-356. doi:10.1016/j.dr.2013.08.002

Yonge, G. D. (1966). Structure of experience and functional fixedness. Journal of Educational Psychology, 57(2), 115-120.

Yu, Y., \& Kushnir, T. (2014). Social Context Effects in 2-and 4-Year-Olds' Selective Versus Faithful Imitation. Developmental Psychology, 50(3), 922-933. doi:10.1037/a0034242 